\title{
INJURY PREVALENCE OF NETBALL PLAYERS IN SOUTH AFRICA: THE NEED FOR INJURY PREVENTION
}

\begin{abstract}
This study aimed to establish baseline data for injury prevalence, mechanism of injury, injury severity and management of injuries in netball players in South Africa. A cross sectional descriptive design was employed to collect data by means of a questionnaire in 2010. Participants consisted of 254 netball players who participated in a netball tournament. Permission was obtained from all the relevant organizations and informed consent obtained from the participants. The general injury rate was $61.8 \%$ with an injury rate of 1.9 injuries per player for the past season. The most commonly injured structures were the ankle $37.5 \%$ and the knee $28.6 \%$ with the most common mechanism of injury being landing, $19 \%$ and $29 \%$ respectively. Of those who sustained injuries, 86 (44\%) of the injured athletes'sustained severe injuries, 31(16\%) sustained moderate injuries and $78(40 \%)$ sustained mild injuries. $67 \%$ of players reported they were able to continue with the game and $33 \%$ received medical assistance losing game and training time. The most common form of management accessed was physiotherapy, which accounted for 31\%. It is evident that the ankle and knee injury rates amongst South African netball players are high in comparison to other netball playing nations. Injury surveillance is an integral part of developing preventative measures. The article lays a platform for developing these strategies against the backdrop of its findings and comparison with other authors.
\end{abstract}

\section{KEY WORDS: INJURY PREVALENCE, NETBALL, MECHANISM OF INJURY.}

\section{INTRODUCTION}

South Africa is a country that is unified by sport and this has been central to our nation building process through victories celebrated such as the 1995 Rugby World cup celebrated with our beloved Nelson Mandela. Netball in particular has received much support from the government, having being recognized as a very popular woman's sport with high rates of participation. Linked to the high participation in the sport is a high prevalence of injuries. However, literature has shown that if effective injury prevention strategies are not in place, then the benefits of sport and in particular in relation to non-professional sporting codes, may be lost (Chalmers 2002). As injury prevention has become a major public health issue, the lack of systematic collection of sports injury-related data, particularly at a non- professional level, is of concern both nationally and internationally thus creating a vacuum of validated data that forms the basis of injury prevention models (Chalmers 2002; Macera and Pratt 2000). To counteract this negative effect by means of preventative pro- grammes, the extent and nature of the sports injury problem needs to be identified to define target groups for prevention (Emery et al 2006).

Sport injuries are a cost burden on both individuals and society with respect to the duration and nature of treatment, the amount of sport and working time lost, permanent damage and disability, reduced quality of life and monetary costs (Parkkari et al 2011). It is therefore evident that preventative measures with regard to injury prevention strategies within South African sport are needed. Netball is a physically demanding game that requires high levels of endurance, strength, speed, power, agility and flexibility (Murphy 1998). It has a high impact on joints due to the stop-start nature of the sport and the aerial requirements further predispose joints to injuries with considerable forces associated with landing. Steele and Milburn (1987) noted vertical ground reaction forces up to 6.8 $\mathrm{x}$ the body weight during landing. Joint motion and muscle activity are important in decreasing the impact forces associated with landing (McNitt-Gray 1991).
Thus an understanding of these factors and mechanisms of injury can contribute to designing effective prevention and rehabilitation programmes.

Van Mechelen and Verhagen (2005) reported that measures to prevent sports injuries in young people should be based on knowledge of the incidence, likely severity of the particular injury and mechanisms that contribute to the risk of sustaining sport-related injuries. Once identified, preventive measures should be implemented and their efficacy evaluated. The authors emphasise that this process is important for all health professionals involved in sports medicine including physiotherapist. The aim of this study was to establish baseline data for injury prevalence, mechanism of

\section{Correspondence Author:}

Tanushree Pillay

47 Villeria Plataan Road,

Durbanville

7550

Cape Town

Email: tanushreeza@yahoo.com 
injury, injury severity and management of injuries in netball players in South Africa, in order to establish a platform for further research in developing preventative measures.

\section{METHODS}

The study employed a cross-sectional, descriptive design as this presents a good framework to collect data on individual characteristics, including exposure to risk factors, alongside information about the outcome of injuries sustained. In this way cross-sectional studies provide a 'snapshot' of the outcome and the characteristics associated with it, at a specific point in time. The population for this study was netball players participating in a national netball tournament in South Africa during the 2010 netball season. Players represented 38 out of the 62 netball playing regions in South Africa. The total number of players at the tournament was 360 and all were invited to participate in the study. The questionnaire used in this study was based on injury prevalence questionnaires that had been validated in previous studies (Walker 2010; Louw et al 2003). An injury was defined as any physical complaint sustained by a player that occurred during a match or training, irrespective of the need for medical attention or time loss from practices and matches (Fuller et al 2006). The main categories determined were exposure time, type and location of the injury, injury severity and injury management. The revised version of the questionnaire was piloted for content validity using experts in the area of injury prevention and for face validity using a sub-sample of netball players $(n=20)$. Reliability testing of the responses was done using a one-week test - retest technique on a subset of netball players $(n=20)$. The responses were compared to assess the players' ability to recall their injury occurrence. There was $100 \%$ agreement on $90 \%$ of the variables.

Ethical clearance was obtained for the study from the ethics committee of the University of the Western Cape. (Ref.: $11 / 1 / 22$ ) and permission to conduct the study was obtained from Netball SA and the tournament officials. Informed written consent was obtained from all the participants prior to completion of the questionnaire and confidentiality and anonymity was ensured to all participants in a written letter detailing the purpose and procedures of the study. These were sorted into packs for each region together with stationery to complete the questionnaire and were handed to each region's manager. Managers were briefed at the manager's meeting on day one of the three day tournament and were given a time and place for collection of the completed questionnaires. The packs were consolidated against the register of participating teams and all packs were collected including those not completed. Data was analysed using SAS V9 (SAS Inc. Cary, USA). Descriptive statistics were used and results are presented as percentages, means and standard deviations.

\section{RESULTS}

The total sample consisted of 254 netball players of which 55 were club players, 147 provincial players and 52 national players, thus yielding a response rate of $71 \%$. Table 1 summarises the ages, starting age and playing years per each division.

The mean number of weekly training sessions reported was 3.7 and the mean number of gym sessions per week was 3.4 with at least 2 match days per week at all levels. Of the total number of participants, $61.8 \%(n=157 / 254)$ of players reported an injury within the last season. The injury prevalence at various levels was $54.5 \%(n=30 / 55)$ at club level, 59.2\% ( $\mathrm{n}=84 / 147)$ among provincial players and $84.3 \%(n=43 / 52)$ amongst national players.

The injury prevalence according to body region is presented in Table 2 . Among the 157 injured players, 301 injuries were reported for the last season resulting in an injury rate of 1.9 injuries per player for the past season. The most commonly injured structures were the ankle and the knee.

Of the most commonly reported injuries (ankle and knee), the relationship between the playing position and the commonly reported positions are reflected in Table 3.

Provincial players sustained the highest percentage of ankle injuries $56.7 \%$, followed by club players $(22.5 \%)$ and national players $(20.8 \%)$. In contrast, provincial players had the highest prevalence of knee injuries (61\%), followed

Table 1: Sample description by age $(\mathrm{N}=254)$

\begin{tabular}{|c|c|c|c|c|c|c|}
\hline Playing level & $\mathbf{n}$ & Label & Mean & STD Dev. & Min & Max \\
\hline \multirow[t]{3}{*}{ Club } & 55 & Age & 24.13 & 6.27 & 16.00 & 44.00 \\
\hline & & Starting age of playing & 12.01 & 3.24 & 6.00 & 21.00 \\
\hline & & Years played & 12.11 & 6.23 & 0.00 & 28.00 \\
\hline \multirow[t]{3}{*}{ Provincial } & 147 & Age & 23.89 & 5.10 & 14.00 & 42.00 \\
\hline & & Starting age of playing & 11.48 & 4.61 & 5.00 & 33.00 \\
\hline & & Years played & 12.40 & 6.15 & 0.00 & 31.00 \\
\hline \multirow[t]{3}{*}{ National } & 52 & Age & 24.32 & 4.25 & 18.00 & 36.00 \\
\hline & & Starting age of playing & 11.23 & 4.66 & 7.00 & 28.00 \\
\hline & & Years played & 13.09 & 5.30 & 1.00 & 26.00 \\
\hline
\end{tabular}


by national players $(26 \%)$ and club players $(13 \%)$. The most common mechanism of injury for both the knee and the ankle injuries were landing with $19 \%$ and $29 \%$ respectively. Tripping accounted for $8 \%$ of injuries in the ankle and $6 \%$ in the knee. The most common surface on which injuries occurred was outdoor concrete (29\% and 13\%) respectively among the knee injuries and ankle injuries.

Ankle and knee injury characteristics were classified as mild, moderate and severe according to symptoms reported by the participants and then further categorized by the researcher. Among the injured participants, 86 (44\%) of the athletes' sustained severe injuries, $31(16 \%)$ sustained moderate injuries and $78(40 \%)$ sustained mild injuries. Based on the injury severity, $67 \%$ of players reported they were able to continue with the game and 33\% had to receive medical assistance together with a loss of game and training time. Of those athletes injured, $55 \%$ had access to professional help. The most common form of management accessed was physiotherapy, which accounted for $31 \%$, followed by doctor's consultation (17\%). Medical personnel cleared $66 \%$ of injured athletes for return to play after sustaining an injury. $32.43 \%$ of club players accessed professional help in comparison to the $60.19 \%$ of provincial players and $73.81 \%$ of national players.

\section{DISCUSSION}

Limited literature exists on the prevalence of injuries among netball players in South Africa. This study highlighted an injury prevalence ranging from $55 \%$ at club level to $84 \%$ amongst national players with an injury rate of 1.9 injuries per player over one netball season. This injury rate is higher (1.1) than that compared to the study by Hume and Steele (2000) but lower (2.6) than the study by McManus, Stevenson and Finch (2006).

Table 2: General injury rate $(\mathrm{N}=301)$

\begin{tabular}{|l|c|}
\hline Body Region & $\%(\mathrm{n})$ \\
\hline Ankle & $37.5(113)$ \\
\hline Knee & $28.6(83)$ \\
\hline Lower leg, calf & $7.3(22)$ \\
\hline Hand, wrist & $6.7(20)$ \\
\hline Shoulder & $6.0(18)$ \\
\hline Back & $4.7(14)$ \\
\hline Thigh & $3.3(10)$ \\
\hline Head, Neck, Chest & $3.0(9)$ \\
\hline Elbow, arm & $3.0(9)$ \\
\hline
\end{tabular}

Table 3: Reported ankle and knee injuries per playing position

\begin{tabular}{|l|l|l|}
\hline Playing position & $\begin{array}{l}\text { No. of ankle injuries reported } \\
(\mathbf{n}=\mathbf{1 1 3})\end{array}$ & $\begin{array}{l}\text { No. of knee injuries } \\
(\mathbf{n}=\mathbf{8 3})\end{array}$ \\
\hline Wing attack (37) & $19 \%(n=21)$ & $12 \%(n=10)$ \\
\hline Centre (46) & $16 \%(n=19)$ & $28 \%(n=23)$ \\
\hline Wing Defense (33) & $15 \%(n=17)$ & $6 \%(n=5)$ \\
\hline Goal attack (37) & $15 \%(n=17)$ & $19 \%(n=16)$ \\
\hline Goal Defense (38) & $13 \%(n=15)$ & $14 \%(n=12)$ \\
\hline Goal shooter (28) & $12 \%(n=14)$ & $14 \%(n=12)$ \\
\hline Goal Keeper (22) & $10 \%(n=11)$ & $6 \%(n=5)$ \\
\hline
\end{tabular}

The distribution of injuries across one season in the current study highlighted the ankle (37.5\%) and knee joint (28.6\%) as the most commonly injured structures. These findings compare similarly to a recent study conducted by Ferreira and Spamer (2010) in South African among university netball players who reported an injury prevalence of $39 \%$ and $28 \%$ respectively for the ankle and knee across one season. A longitudinal study conducted by Hopper, Elliot and Lalor (1995), over a period of five years in Australia, also reported high ankle injury prevalence. It is thus evident that the ankle and knee are the most common joints injured in netball and thus needs effective injury prevention strategies as these structures are subjected to increased physical stress during the sport.

The primary mechanisms of injury were tripping and landing for both the ankle and knee injuries, which are similar to the findings in other studies by Ferreira and Spanner (2010). Landing has been reported as being directly related to injuries in the joints of the lower extremity (Hewett et al 1999) and was one of the primary causes of lower limb netball injuries. Hopper (1986 and Steele (1990) recommended that all netball players regardless of age, should incorporate specific landing techniques to ensure that players use correct body mechanics when landing, especially after striding forward to receive a pass in order to minimize injury.

The majority of injuries reported were considered either severe $(44 \%)$ or mild $(40 \%)$. This even distribution of mild and severe injuries highlights the need for effective education and prevention strategies linked to the management of all injuries with varying severity. A shortcoming of this study is that the diagnosis of an injury cannot be confirmed, as injuries were self reported, and thus the characteristics of the injury may have lead to the injury being categorized into a classification more severe than what it could have been on further diagnosis. $55 \%$ of the injured sample accessed professional help with $31 \%$ of netball players attending a consultation with a physiotherapist. This could possibly be due to the high number of mild injuries reported. However, if left 
untreated or inadequately managed, the ramifications of minor injuries at club level could impact severely at a national tier by predisposing to further injury.

This highlights a need for sport medicine professionals to focus on preventative measures as well as health promotion and injury prevention education within South African communities. Although preventative solutions are known to be multifaceted, there is a need for a concerted and coordinated intra-and intersectoral approach to reducing the magnitude and frequency of the burden of injury in netball. A motivation for this is to ensure that sports medicine adopts best practice principles to dealing with injury prevention. To date, preventative sports medicine has largely ignored the issue of how best to translate research evidence into effective interventions that have high adoption levels and there is a major gap in the international literature about how best to engage the target groups in sport safety to develop and implement injury prevention policies and practices. Consequently, there is very little guidance to inform decision - making or for identifying appropriate injury prevention strategies for specific sporting codes.

\section{CONCLUSION}

Injury surveillance is an integral part of developing preventative measures and if physiotherapists are to influence sports injury prevention policies, there is a need for baseline data in order to inform prevention strategies.

\section{REFERENCES}

Chalmers DJ 2002. Injury Prevention in Sport: Not Yet Part Of The Game. Injury Prevention (IV): iv22-iv25

Emery CA, Meeuwisse WH, McAllister JR. 2006. Survey of sports participation and sports injury in Calgary and area high schools. Clinical Journal of Sports Medicine (16): 20-26

Ferreira MA, Spamer EJ 2010. Biomechanical, Anthropometrical and Physical Profile of Elite University Netball Players and the Relationship to Musculoskeletal Injuries. South African Journal for Research in Sport, Physical Education and Recreation. 32(1): 57-67.
Finch C 2006. A new framework for research leading to sport injury prevention. Journal of Science and Medicine in Sport. 9(1-2): 3-9

Finch C, Donaldson A 2010. A sport-seeking matrix for understanding the implementation context for community sport. British Journal of Sport Medicine. 44(13): 973-978

Fuller CW, Ekstrand J, Junge A, Andersen T, Bahr R, Dvorak J, Hagglund M, McCrory P, Meeuwisse W 2006. Consensus statement on injury definitions and data collection procedures in studies in football (soccer). British Journal of Sport Medicine. (40): 193-201

Hewett T, Lindendfeld T, Riccobene J, Nayes F 1999. The effect of neuromuscular training on the incidence of knee injury in female athletes. A prospective study. American journal of sport medicine. Vol 27 no 6.

Hopper D, Elliot B, Lalor J. 1995. A descriptive epidemiology of netball injuries during competition: A five-year study. British Journal of sport medicine. (29): 223-228

Hopper D 1986. A survey of netball injuries and conditions related to these injuries. Australian Journal of Physiotherapy (32): 231-9

Hume P, Steele J 2000. A preliminary investigation of injury prevention strategies in netball: Are players heeding the advice. Journal of Science and Medicine in Sport. 3(4): 406 - 413.

Kostopolus N, Dimitrios P. (2010). Injuries in Basketball. Biology of Exercise. (6.1): 47-55

Louw Q, Grimmer K, Vaughan K 2003. Knee Injury Patterns Among Young Basketball Players in Cape Town. South African Journal of Sports Medicine. 18(1): 9-15

Macera C, Pratt M 2000. Public health surveillance of physical activity. Res Q Exerc Sport 71(2): $97-103$.

McManus A, Stevenson M, Finch C 2006. Incidence and risk factors for injury in non-elite netball. Journal of Science and Medicine in Sport 9(1-2): 119-124

McNitt-Gray JL 1991. Kinematics and Impulse Characteristics of Drop Landings from Three Heights. International journal of Biomechanics (7): 201-224.

Murphy LA 1998. Train for success: strength and conditioning for netball. Victoria, Australia: Bouquet Productions.
Parkkari J, Kujala U, Kannus P. 2001. Is it possible to prevent sports injuries? Review of controlled clinical trials and recommendations for future work. Sports Med 31 (14): 985-995.

Steele JR 1990. Biomechanical factors affecting performance in netball. Implications for improving performance and injury reduction. Sports Medicine, (10): 88 - 102 .

Steele JR, Milburn PD 1987. Ground reaction forces on landing in netball. Journal of Human Movement Studies (13): 399- 410

Van Mechelen W, Verhagen E 2005. Essay: Injury prevention in young people - time to accept responsibility. Medicine and Sport. Vol 366. www. thelancet.com

Walker S 2010. Exploring the relationship between floor type and risk of injury in netball. The University of South Australia. http://sportsurf. lboro.ac.uk/workshops/STARSS/SE/SW.pdf 